\title{
Advances in neoadjuvant therapy for resectable pancreatic cancer over the past two decades
}

\author{
Alvaro Gregorio Morales Taboada ${ }^{1,2}$, Pablo Lozano Lominchar ${ }^{1}$, Lorena Martin Roman ${ }^{1}$, \\ Pilar García-Alfonso ${ }^{3}$, Andres Jesús Muñoz Martin ${ }^{3}$, \\ Jose Antonio Blanco Rodriguez ${ }^{4}$, and Jose Manuel Asencio Pascual ${ }^{1,2}$ \\ ${ }^{1}$ Department of General and Digestive Surgery, Hospital General Universitario Gregorio Marañon, \\ Complutense University of Madrid, ${ }^{2}$ Transplant and Hepatobiliopancreatic Surgery Unit, \\ Department of General and Digestive Surgery, Hospital General Universitario Gregorio Marañón, \\ Departments of ${ }^{3}$ Medical Oncology and ${ }^{4}$ Radiation Oncology, Department of Oncology, \\ Hospital general Universitario Gregorio Marañon, Complutense University of Madrid, Madrid, Spain
}

\begin{abstract}
In the last two decades, pancreatic cancer has been undergoing important changes in its perioperative management due to the great interest in multidisciplinary management and preoperative multimodal therapy, which in numerous studies have shown promising clinical results. Although the standard of treatment for resectable pancreatic ductal adenocarcinoma (PDAC) today is surgery followed by adjuvant therapy, as it is a biologically aggressive disease, even with complete resection, it has high rates of local and distant relapse. Several retrospective and prospective phase $\mathrm{I} / \mathrm{II}$ studies have opened the window for neoadjuvant therapy with chemotherapy (CT), chemoradiotherapy (CRT), or both, as an alternative treatment for resectable pancreatic cancer, with promising results. Neoadjuvant therapy could has some advantages, including early administration of systemic treatment, in vivo assessment of response to treatment, increase resectability rate in borderline patients, increase resection rate with negative margin and survival benefit. While it seems clear that even potentially resectable disease would benefit from preoperative multimodal therapy, the optimal neoadjuvant therapeutic strategy is still controversial and currently there are only recommendations for neoadjuvant treatment, in clinical guidelines such as the NCCN and ESMO, for borderline and/or locally advanced PDAC. This review provides an overview of recent studies available and how they relate to systemic treatment of resectable PDAC in the neoadjuvant setting. (Ann Hepatobiliary Pancreat Surg 2021;25:179-191)
\end{abstract}

Key Words: Resectable disease; Pancreatic ductal adenocarcinoma; Neoadjuvant therapy; Chemotherapy; Chemoradiotherapy

\section{INTRODUCTION}

Pancreatic ductal adenocarcinoma (PDAC) is the fourth most common cause of cancer death in men and women (behind lung, colon, and prostate cancers in men and breast cancers in women) in both the United States and Europe, with more than 48,000 deaths per year and more than 35,000 per year respectively. Following this line, it will probably become the second leading cause by 2030 , surpassed only by lung cancer. ${ }^{1}$

It is considered one of the most aggressive neoplasms, with a survival rate below $5 \%$ at 5 years. Most patients are diagnosed with advanced disease, 5-10\% have limited or locally advanced resectable disease, and only $15-20 \%$ of patients are considered candidates for curative resection from the beginning. Although surgical resection is currently considered the only potentially curative treatment, resection alone is not sufficient, resulting in low cure rates, with a 5 -year survival of $7-25 \%(10 \%)$ with a median survival of 11-20 months. ${ }^{2,3}$

These data clearly show that surgery alone cannot significantly improve the survival of patients affected by pancreatic cancer and therefore other complementary treatments such as chemotherapy, radiotherapy or both have been tried in a multimodal approach. The choice of treatment modality, either individually or in combination, will

Received: December 1, 2020; Accepted: December 31, 2020

Corresponding author: Alvaro Gregorio Morales Taboada

Department of General Surgery, Liver Transplant Unit, Gregorio Marañon University General Hospital, c/ O’Donnell, 6, Madrid 28009, Spain Tel: +11-0034912407568, E-mail: alvarogmt@gmail.com

Copyright (C) 2021 by The Korean Association of Hepato-Biliary-Pancreatic Surgery

This is an Open Access article distributed under the terms of the Creative Commons Attribution Non-Commercial License (http://creativecommons.org/ censes/by-nc/4.0) which permits unrestricted non-commercial use, distribution, and reproduction in any medium, provided the original work is properly cited. Annals of Hepato-Biliary-Pancreatic Surgery • pISSN: 2508-5778 - eISSN: 2508-5859 
depend on stage, size of the tumor, patient-related factors such as functional status, comorbidity, toxicity and patient preference. ${ }^{4}$

The Gastrointestinal Study tumor Group was the first to demonstrate a survival benefit with adjuvant chemoradiation in pancreatic cancer. Then, several studies phase II-III trials showed good results in favor of adjuvant chemotherapy with different schemes, like CONKO-001 trial (Charité Onkologie 001), compared gemcitabine group vs. observation group. This study showed a statistically significant difference in survival (median overall survival (OS) 22.8 vs. 20.2 months, respectively, median deseasefree survival (DFS) 13.4 vs. 6.9 months). The ESPAC-4 trial (European Study Group for Pancreatic Cancer 4) also demonstrated evidence of benefit from adjuvant chemotherapy, with a median overall survival for patients in the gemcitabine plus capecitabine group of 28.0 months, compared with 25.5 months in the only gemcitabine group, suggesting additional benefit from combining gemcitabine and capecitabine, proposing it as a new standard after resection. More recently, the PRODIGE-24 trial randomized 493 patients to receive mFOLFIRINOX or gemcitabine in adjuvant setting. The mFOLFIRINOX regimen showed a longer survival than gemcitabine (median OS was 54.4 vs. 35.0 months, median DFS 21.6 vs. 12.8 months, respectively). These studies, all in the adjuvant setting, demonstrated improvements in terms of DFS and OS. ${ }^{5-9}$ Despite encouraging results, still about $25-48 \%$ of PDAC patients treated with curative resection, fail to receive planned adjuvant treatment due to complications, low-status performance, rejection or early recurrence. ${ }^{10-12}$ Even with the addition of adjuvant therapy $(\mathrm{CT}+/-\mathrm{RT})$ after surgery, there is a high risk of systemic and/or local recurrence of approximately $63 \% .^{13}$ This has led to a greater focus on the use of neoadjuvant therapy for patients without evidence of metastatic disease. Although resectable disease by radiological criteria shows no clinical evidence of distant disease, it is believed to be micrometastatic in onset, with up to $17 \%$ having hidden metastatic disease identified at the time of surgery and more than $70 \%$ of patients having nodal metastases in the post-resection anatomopathological study. ${ }^{14,15}$

The different preoperative CT and CRT regimens have been evaluated in a small number of studies, most of which have methodological limitations and are not ran- domized. Even so, preoperative treatment has been evolving, and continues to be a topic of debate, showing multiple promising benefits, including early treatment of hidden micrometastatic disease, improved compliance with chemotherapy, the potential to reduce tumors and increase resection rates with a negative margin, as well as better selection of patients likely to benefit from surgery or not. ${ }^{6,7,16}$ However, as the generalization of retrospective reports is clearly limited and the role of neoadjuvant treatment (NAT) in PDAC is still under debate due to a relative lack of robust data. More prospective data are needed to evaluate this strategy in the population with early resectable disease.

The main goal of this review article is to collect and update existing information and ongoing trials focusing on neoadjuvant therapy in resectable PDAC.

\section{METHODS}

A PubMed online search was performed using the following search keywords alone or in combination: Resectable disease, pancreatic ductal adenocarcinoma, neoadjuvant therapy, chemotherapy, chemoradiotherapy. All studies in last two decades were reviewed for inclusion or not, in this manuscript especially clinical trials Phase II, but borderline and locally advanced pancreatic cancer articles, were excluded. We reviewed only data into resectable pancreatic cancer. Furthermore, the ClinicalTrials.gov database was explored to identify prospective ongoing trials. The purpose of this review was to provide an overview of current data for neoadjuvant therapy in the treatment of resectable pancreatic cancer and new developments and future directions for this approach.

\section{STAGING}

The ability to accurately stage patients is essential to the development and evaluation of stage-specific therapies and thus maximize outcome and quality of life for all patients. The American Joint Committee on Cancer (AJCC) TNM staging has been used to characterize the pathological stage of pancreatic cancer. This system evaluates the status of the primary tumor $(\mathrm{T})$, lymph nodes $(\mathrm{N})$, and metastases (M) with the goal of defining tumor stages and providing a prognosis based on severe pathologic features. 
The update in the classification of the AJCC 8th edition responds to criticisms of previous versions with several changes in the $\mathrm{T}$ and $\mathrm{N}$ categories, with the current main objective as previously stated of providing information on the prognosis of the disease in particular, rather than guiding the management of the patient. In the eighth edition, the $\mathrm{T}$ stage ( $\mathrm{T} 1$ to $\mathrm{T} 4$ disease) is based almost entirely on tumor size, i.e., only the extent of the tumor beyond the pancreas is no longer considered T3. Subdivisions have also been added to $\mathrm{T} 1(\mathrm{~T} 1 \mathrm{a} \leq 0.5 \mathrm{~cm}, \mathrm{~T} 1 \mathrm{~b} 0.5-1 \mathrm{~cm}$, and T1c 1-2 cm in its largest dimension). The size criteria for the T2 and T3 categories have been modified (T2 defined as $>2$ and $\leq 4 \mathrm{~cm}$ and $\mathrm{T} 3$ defined as tumors $>4$ $\mathrm{cm}$ in its largest dimension), and T4 disease has been defined as any tumor involving the celiac axis (CA), superior mesenteric artery (SMA) or common hepatic artery (CHA), regardless of the size of the tumor. The $\mathrm{N}$ category is now stratified according to the number of regional lymph nodes involved identified at the time of surgical resection and histopathology evaluation. $\mathrm{N} 1$ is defined as pathologically proven metastases in three or less regional lymph nodes and $\mathrm{N} 2$ as proven metastases in four or more regional lymph nodes. The criteria for $\mathrm{M}$ as absence (M0) or presence (M1) of distant metastases did not change. ${ }^{17}$

With the advent of neoadjuvant therapy for pancreatic cancer, alternative staging systems began to be developed based on preoperative parameters that more accurately rank the likelihood of surgical resection by assessing anatomic factors and the ability to achieve complete surgical resection. This classification of the tumor-mesenteric vessel relationship is a critical component of surgical planning and is not addressed in the AJCC staging system. Staging is usually performed with three-phase computed tomography (CT) scan (pancreatic protocol) of the chest, abdomen, and pelvis. Based on the images, the tumor can be classified as resectable, borderline resectable, locally advanced (type A or B), and metastatic. Although there is close agreement on what constitutes resectable and unresectable disease (locally advanced and metastatic), the definition of resectable borderline disease is more variable. ${ }^{18}$

Multiple staging systems have been described from a variety of different societies and institutions. In general, resectable or localized disease occurs when there is no arterial tumor contact with the celiac axis (CA), superior mesenteric artery (SMA) or common hepatic artery (CHA) and no tumor contact with the superior mesenteric vein $(\mathrm{SMV})$ or portal vein $(\mathrm{PV})$ or $\leq 180$ (Table 1$).{ }^{19-23}$

\section{RATIONALE OF NEOADJUVANT TREATMENT IN RESECTABLES PANCREATIC CANCER}

Pancreatic cancer could be considered an aggressive disease from the beginning, resulting in recurrent disease within 2 years after resection in most of patients. Studies focusing on recurrence patterns have demonstrated that the initial recurrence in $76 \%$ of patients was systemic. Therefore, also could be approached as a systemic disease, irrespective of apparent non metastatic disease on imaging. $^{24-27}$

Surgical resection and adjuvant chemotherapy are the only strategy that has improved survival of pancreatic cancer patients during the last 3 decades. ${ }^{28}$ This is based on multiples randomized controlled clinical trials that have demonstrated the benefit of adjuvant therapy in PDAC. Such is the case with CONKO-001 and ESPAC4 which demonstrated an increase in overall median survival when comparing surgery alone versus additional therapy with gemcitabine or gemcitabine and capecitabine. ${ }^{7,8}$ Until recently, the overall survival benefit of adjuvant therapy has been modest. However, the recent GI PRODIGE 24/ CCTG PA.6 report demonstrated a median overall survival of 54 months among patients receiving modified fluorouracil, irinotecan and oxaliplatin (mFOLFIRINOX) compared to patients receiving gemcitabine (35 months). This is undoubtedly an important difference in survival compared to those from initial surgery, but these results should be interpreted with caution as the benefit may be explained by selection bias. Despite promising results, postoperative period remains a major problem specially in pancreatic head resections, observing even in high volume centers, that almost half of the patients will not receive or complete postoperative adjuvant treatment due to postoperative complications, delayed recovery, early disease progression and low-performance status. This has led to a greater emphasis on the use of neoadjuvant therapy for patients without evidence of metastatic disease. ${ }^{9,29,30}$ The neoadjuvant approach, gives the chance of receive CT treatment in most of medically fit patients.

Conceptually, preoperative multimodal therapy (chemo- 


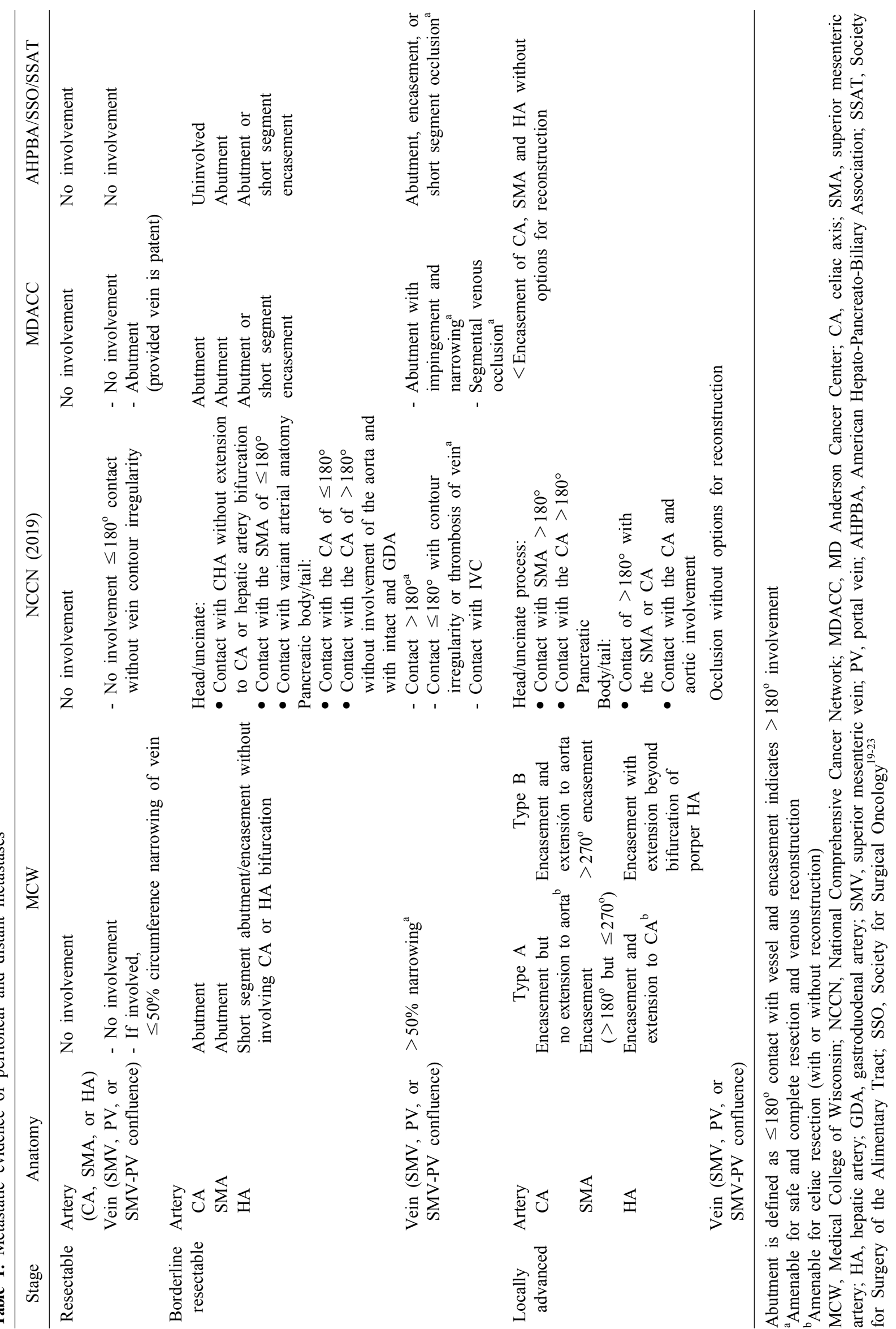


therapy, chemo-radiotherapy or both) may offer several theoretical and practical advantages. First one could be the benefit of giving preoperative treatment in a well-oxygenated, non-devascularized tissue and therefore more susceptible to the effects of chemotherapy and radiation. Another benefit is improved tolerance of treatment initiation because patients are not recovering from the physiological and immunological disorders of a major surgical procedure. In addition, the possibility of administering full doses of CT and/or RT is much greater when given before surgery. Recent studies report compliance rates with full-dose neoadjuvant chemotherapy of $90-100 \%$, as opposed to $66.4 \%$ in the modified-FOLFIRINOX group or $79.0 \%$ in the gemcitabine group, in the recent multicenter, randomized, open-label, phase 3 trial (PRODIGE 24ACCORD 24/CCTG PA.6) with adjuvant therapy. The progression of the disease in the post-treatment re-evaluation allows to select patients who would benefit from surgical treatment, thus assessing the sensitivity to chemotherapy, thus saving the morbidity and possible mortality of a non-therapeutic laparotomy (median survival after progression of 7 months, without improvement after surgery if the resection is possible). In relation to the quality of resection, neoadjuvant therapy could potentially have an impact of lymphatic node status, improve the rate of R0 resection, and even convert tumors considered unresectable into resectable after reassessment conferring a survival benefit, although in a very select group of patients, as shown by a recent Dutch phase III study with a better $\mathrm{R} 0$ resection rate, $71 \%$ in patients who received preoperative chemoradiotherapy vs. $40 \%$ in patients assigned to immediate surgery $(p<0.001){ }^{31-34}$

On the other hand, there are also several arguments against neoadjuvant therapy for resectable disease. It delays surgery, especially when patients experience significant complications such as biliary occlusion, being a potential drawback because biliary drainage is required before chemotherapy. Furthermore, biliary drainage is associated with mainly infectious complications. ${ }^{35}$ Perhaps the greatest concern with a neoadjuvant approach is that patients with potentially resectable disease may have local disease progression (11\%), making them unresectable, missing a potentially curative surgical opportunity. However, the risk of disease progression during neoadjuvant therapy should be analyzed as part of the optimal se- lection of good candidates to benefit from surgery, avoiding futile surgery in patients with rapidly progressive disease. $^{36}$ Other disadvantages and/or concerns unlike surgery, would be the need for a positive histological diagnosis. This can be elusive and risky given the cancer's anatomic location as well as its structure and can thus postpone therapy. ${ }^{37}$

In the last two decades neoadjuvant therapy is beginning to be used in the context of borderline, locally advanced (advised in the latest NCCN clinical guidelines), or resectable tumors with high-risk factors such as a considerable elevation of CA19.9, large tumors, significant regional adenopathy in preoperative tests or tumor-related symptoms. $^{20,38}$

Experience to date with neoadjuvant therapy suggests that it is a promising strategy as part of multimodal therapy, for a high percentage of patients, but its use for resectable pancreatic cancer is still a matter of debate because there is not a robust evidence base. Some clinical trials continue evaluating the utility of this strategy.

\section{CLINICAL EVIDENCE OF NEOADJUVANT TREATMENT FOR RESECTABLE PANCREATIC CANCER}

Until recently, the evidence for a neoadjuvant therapeutic approach to resectable pancreatic cancer has been limited to single-arm retrospective and prospective studies. In fact, several studies have shown benefits in favor of neoadjuvant treatment, especially those in which treatment was completed and resected. ${ }^{39-42}$ In the last two decades, evidence to support neoadjuvant chemoradiation was established from several phase II trials. It is important to recognize two caveats when interpreting the data from these neoadjuvant therapy studies. First, the definition of resectable PDAC was generally arbitrary and judged by one surgeon as the primary inclusion criteria for trials conducted before 2000. A second caveat is that our ability to correctly stage pancreatic cancer has changed over time, with improved imaging scan, leading to possible stage migration. For example, even within phase II MD Anderson Cancer Center trials, the trend toward improved median survival over time could be the result of improved patient selection.

There is much written about neoadjuvant therapy in re- 
sectable borderline, and locally advanced, but few studies have focused only on resectable pancreatic cancer, where there is currently debate about accepting evidence, although inconsistent, with a marked tendency to improve outcomes in this type of patient by increasing resectability rates, assessing patient sensitivity to treatment, and increasing survival. During the last two decades some studies have shown benefits after neoadjuvant therapy in resectable patients, improving the median overall survival in almost 12 months in those patients who complete neoadjuvant therapy and undergo complete surgery. This is a remarkable finding since it is considered that the increase in survival is not due to new therapies, but rather to a change in treatment approach. ${ }^{43-46}$

Most of the evidence in this area is based on phase II studies based on combined chemotherapy regimens with 5-fluorocyl, irinotecan, oxaliplatin, gemcitabine with or without paclitaxel, docetaxcel and capecitabine, alone or associated with radiotherapy (Table 2).

Pisters et al. ${ }^{47}$ published a prospective phase II study
(2002), with 35 patients with localized pancreatic adenocarcinoma potentially resectable at MD Anderson Cancer Center (MDACC), whose main objective was to evaluate the toxicity of neoadjuvant therapy with concurrent chemoradiation (CCRT) with Paclitaxel+RT (30 Gy)+Intraoperative radiation therapy (IORT) of the 35 patients, 16 experienced toxicity, $57 \%$ were successfully resected and of these, $60 \%$ with negative margin (R0), with a follow-up of 3 years, an overall survival of $28 \%$ was observed, with a median survival of 19 months. The authors concluded that this regimen was no more toxic than the 5 fluorocyl and that it did not provide advantages.

Later on, another phase II multinational study involving 5 institutions, led by Northwestern University Chicago (Talamonti et al. ${ }^{48}$ 2006), analyzed 20 patients with resectable pancreatic cancer with confirmation of PDAC by biopsy, subjected to CCRT at full dose of gemcitabine. The planned course of radiation was $36 \mathrm{~Gy}$ in 2.4 fractions to the macroscopic tumor. Up to $85 \%$ (17 patients out of 20) achieved resection with a median survival of 26

Table 2. Selected clinical trials of neoadyuvant therapy for resectable pancreatic cancer

\begin{tabular}{|c|c|c|c|c|c|c|c|}
\hline Author & Year & $\mathrm{N}$ & Neoadjuvant regimen & $\begin{array}{l}\text { Resected } \\
\quad(\%)\end{array}$ & $\begin{array}{l}\text { Resected } 0 \\
(\%)\end{array}$ & Survival & Clinical trial \\
\hline \multicolumn{8}{|l|}{ Chemoradiotherapy } \\
\hline$*$ Pisters et al. $^{47}$ & 2002 & 35 & $\begin{array}{l}\text { CCRT } \\
\text { Paclitaxel+RT (30 Gy)+IORT }\end{array}$ & 57 & 68 & $\begin{array}{l}28 \%(3-y r) \\
19(\mathrm{mo}) \mathrm{R}\end{array}$ & Phase II \\
\hline 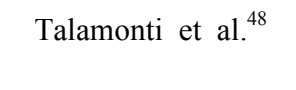 & 2006 & 20 & $\begin{array}{l}\text { CCRT } \\
\text { Gem+RT (36 Gy) }\end{array}$ & 85 & 94 & $26(\mathrm{mo}) \mathrm{R}$ & Phase II \\
\hline *Evans et al. $^{43}$ & 2008 & 86 & $\begin{array}{l}\text { CCRT } \\
\text { Gem, } 400 \mathrm{mg} / \mathrm{m}^{2} \text { weekly } \times 7+\mathrm{RT} \text {, } \\
30 \mathrm{~Gy}\end{array}$ & 74 & 89 & $\begin{array}{l}27 \%(5-\mathrm{yr}) \\
34 \text { (mo) R }\end{array}$ & Phase II \\
\hline \multicolumn{8}{|l|}{$\begin{array}{l}\text { Chemottherapy } \\
\text { followed by } \\
\text { chemoradiation }\end{array}$} \\
\hline *Varadhachary et al. ${ }^{44}$ & 2008 & 90 & $\begin{array}{l}\text { Gem, } 750 \mathrm{mg} / \mathrm{m}^{2}+ \\
\text { cisplatin } 30 \mathrm{mg} / \mathrm{m}^{2} \rightarrow \text { CCRT } \\
\text { Gem, } 400 \mathrm{mg} / \mathrm{m}^{2}+\mathrm{RT}, 30 \mathrm{~Gy}\end{array}$ & 66 & 96 & $31(\mathrm{mo}) \mathrm{R}$ & Phase II \\
\hline Christians et al. $^{45}$ & 2016 & 69 & $\begin{array}{l}\text { Chemotherapy (various) and } \\
\text { chemoradiation }\end{array}$ & 87 & 97 & $\begin{array}{l}31.5(\mathrm{mo}) \\
44,9(\mathrm{CT})\end{array}$ & Retrospective \\
\hline \multicolumn{8}{|l|}{ Chemotherapy alone } \\
\hline Palmer et $\mathrm{al}^{49}$ & 2007 & 50 & $\begin{array}{l}\text { Gemcitabine vs } \\
\text { Gemcitabine+Cisplatino }\end{array}$ & $\begin{array}{c}\text { Gem: } 38 \\
\text { Gem+Cis: } 70\end{array}$ & $\begin{array}{c}\text { Gem: } 75 \\
\text { Gem+Cis: } 75\end{array}$ & Gem: 42 (1-yr) & Phase II \\
\hline Heinrich et al. ${ }^{50}$ & 2008 & 28 & Gem, $1 \mathrm{~g} / \mathrm{m}^{2}$, Cis, $50 \mathrm{mg} / \mathrm{m}^{2}$ & 93 & 80 & $26.5(\mathrm{mo})$ & Phase II \\
\hline O'Reilly et al. ${ }^{51}$ & 2014 & 38 & Gem, $1 \mathrm{~g} / \mathrm{m}^{2}$, Oxa, $8071 \mathrm{mg} / \mathrm{m}^{2}$ & 71 & 74 & $\begin{array}{l}63 \%(1,5-\mathrm{yr}) \\
27.2(\mathrm{mo})\end{array}$ & Phase II \\
\hline
\end{tabular}

*MDACC Clinical trials Phase II

R, resected; Gem, gemcitabine; Cis, cisplatino; Oxa, oxaliplatino; Gy, gray; IORT, intraoperative radiotherapy; mo, months; yr, years, CCRT, concurrent chemoradiation; RT, radiotherapy; CT, complete treatment 
months in this group. Palmer et al. ${ }^{49}$ observed in a phase II study that neoadjuvant chemotherapy with combined gemcitabine+cisplatin increases the resection rate (RR), and survival in favor of combined therapy of 15.6 months compared to 9.9 months for gemcitabine alone. A similar treatment scheme (gemcitabine+cisplatin) was used by Heinrich et al. ${ }^{50}$ (2008), and also evaluated the quality of life of patients before and after treatment and pathologic response. Complete resection was achieved in 26 patients (93\%), of the 28 that entered the study, with $80 \%$ of resection with free margins (R0), the pathological response was observed in 20 patients, with $45 \%$ local recurrence, and overall survival of 26.5 months (95\% CI, 11.4 to 41.5 months) in an intention-to-treat analysis, and 19 months for resected patients. The authors concluded that neoadjuvant therapy with gemcitabine+cisplatin was feasible, safe and with improved quality of life. The high percentage of local recurrence is probably due to the lack of radiation therapy.

Evans et al. $^{43}$ (MDACC), the same year published a phase II study with 86 patients with resectable pancreatic cancer (stage I/II), who received neoadjuvant therapy with CCRT (gemcitabine $400 \mathrm{mg} / \mathrm{m}^{2} / \mathrm{RT} 30 \mathrm{~Gy}$ ); $85 \%$ went to surgery, but only 74\% (64 patients) successfully completed the resection. Observed a 5-year survival of $27 \%$, with the median survival for the 64 patients who completed the resection of 34 months versus 7 months in unresected patients $(p=0.001)$. What is interesting in this work is the low isolated local recurrences $3 \%$, but systemic recurrence was $47 \%$ (30 patients out of 64 ). Following the basis of this study the same group (MDACC) designed a phase II study by Varadachary, in response to this pattern of recurrence with gemcitabine plus cisplatin before CCRT (gencitabine) in 90 patients who were treated with 4 cycles of chemotherapy, and subsequent chemoradiation with four weekly cycles of gemcitabine and concomitant radiotherapy (30Gy in 10 fractions administered over 2 weeks) 79 patients managed to complete preoperative therapy, but only $52 \%$ completed resection. The median overall survival was 31 months for the patients who underwent duodenopancreatectomy, compared with 10.5 months for patients who did not undergo surgical resection of their primary tumor $(p=0.001)$, and distant recurrence was $42 \%$. Conclusions from this trial were that preoperative chemotherapy with gemcitabine and cisplatin followed by concurrent chemoradiotherapy did not improve survival beyond that achieved with preoperative gemcitabine-based chemoradiotherapy alone. ${ }^{44}$

MDACC researchers have generated the most data using neoadjuvant therapy in the treatment of resectable pancreatic cancer in a series of phase II trials for resectable tumors, where the definition remained the same for all studies. All of these trials demonstrated that patients who completed neoadjuvant chemoradiation and had no radiographic evidence of progression before surgery were more likely to achieve R0 resection compared to historical surgical data, and those who underwent surgical resection demonstrated higher median and OS rates.

Memorial Sloan Kettering Cancer Center, with O'Reilly as principal investigator, conducted a single-arm phase II non randomized study of patients treated with neoadjuvant gemcitabine and oxaliplatin in patients with resectable pancreatic adenocarcinoma, reporting up to $63 \%$ on 18 month survival (24 patients alive), with an overall median survival for the 38 patients included in the study of 27.2 months. $^{51}$

Casadei et al. $^{52}$ and Golcher H. et al. ${ }^{53}$ (2015) conducted an attempt at randomized comparative trials of chemo-radiation+surgery vs. surgery first, both with subsequent adjuvant treatment, but these trials were not completed and were unsuccessful, mainly due to the difficulty of recruitment. Not surprisingly, such clinical trials have failed to meet recruitment targets, as many patients and referring physicians are unwilling to participate in clinical trials (phase II or III) that involve randomization to two dramatically different treatment arms.

Recently, the results of a multicenter randomized phase II/III clinical trial PACT-15 evaluating perioperative PEXG (cisplatin, epirubicin, capecitabine, gemcitabine) in 10 Italian hospitals. A total of 88 patients were randomized to 3 arms. Patients in arm 1 received standard adjuvant gemcitabine for 6 months. Patients in arm 2 received adjuvant PEXG every 14 days for 6 months. Arm 3 includes neoadjuvant and adjuvant PEXG with up to 3 months before surgery and 3 months after surgery. Both preoperative and adjuvant PEXG resulted in more than $40 \%$ of patients being event-free at one year, achieving the primary goal. However, the most relevant results of this trial are the median survival of 38 months and OS of $55 \%$ and $49 \%$ at 3 and 5 years respectively, in favor of arm 3 (periopera- 
tive therapy). These results provide the strongest evidence available to date of the efficacy of neoadjuvant chemotherapy in patients with resectable pancreatic cancer. The study had a phase 2 design and the results cannot be viewed as conclusive. Despite this limitation, the reported advantage of neoadjuvant chemotherapy could lead to a major departure from the traditional approach. due to the change of apparently better adjuvant chemotherapy regimens than PEXG, during the phase 2 part of the PACT-15 trial, the authors decided not continue to phase 3 part. However, they are planning to do a confirmatory phase 3 trial in which the comparator arm is not yet to be identified. $^{54}$

In 2016, the results of a study of 69 patients treated with neoadjuvant therapy with chemotherapy, chemoradiotherapy or both with different gemcitabine doublings (e.g., erlotinib or cisplatin) or FOLFIRINOX outside of clinical trials, were analyzed by the Medical College of Wisconsin (MCW) between 2009 and 2013 whose patients were identified from a prospective institutional database. Reporting a resection rate R0 in 58 (97\%) of the 60 patients undergoing surgery, with a median survival of the 69 patients in the study of 32 months and 45 months for the 60 patients who completed all neoadjuvant treatment+resection, compared with 8 months for the 9 patients who were not resected $(p<0.001)$. ${ }^{45}$ Another similar study by Lutfi et al. ${ }^{55}$ (2017) examined patients with stage I-II PDAC within the National Cancer Data Base between 2006 and 2012. A propensity score matching was used to compare patients receiving neoadjuvant chemotherapy including radiation, observing more likely to have node negative resections $(p<0.001)$ in these patients, with higher perioperative mortality in comparison to those receiving only neoadjuvant chemotherapy, but no long-term overall survival benefit associated.

A propensity matched analysis by Mokdad et al. ${ }^{56}$ (2017) of over 15,000 patients with resectable PDAC from the National Cancer Database demonstrated that neoadjuvant therapy has a significant survival benefit in early-stage, resected pancreatic head adenocarcinoma. The neoadjuvant therapy group demonstrated improved survival compared to the initial surgery group (median OS, 26 months vs. 21 months). Later, two similar studies carried out by Cloyd et al. ${ }^{57}$ and Mokdad et al. ${ }^{58}$ (2019/2018) compared preoperative chemotherapy vs. chemoradiothe- rapy. They observed, preoperative CRT is associated with more margin negative, and less local recurrence, at the cost of higher postoperative morbidity and mortality, but with a similar OS compared with preoperative CT, in contrast with a recent plublished propensity-Matched Analysis of the National Cancer Database for resectable disease (stage I-II) by Xiang et al. ${ }^{59}$ (2020) who compared preoperative chemotherapy alone, chemotherapy with conventionally-fractionated radiation (CFRT), or chemotherapy with stereotactic body radiotherapy (SBRT). The results showed favorable survival and pathological outcomes with SBRT compared to chemotherapy alone (median 30 vs. 21 months, $p=0.02$ ), and compared to CFRT (median 29 vs. 16 months, $p=0.002$ ).

\section{CURRENT NEOADJUVANT TRIALS}

As the optimal neoadjuvant regimen is not yet known, multiple clinical trials are currently evaluating various treatment strategies with more modern chemotherapy regimens in the neoadjuvant setting for resectable pancreatic cancer. Many protocols involve perioperative treatment including neoadjuvant and adjuvant therapy, and many incorporate preoperative radiotherapies in addition to routine chemotherapy. Below are some ongoing studies with a neoadjuvant strategy for potentially resectable pancreatic cancer. The main objectives of these studies are resection rate, number of patients completing the treatment sequence, disease-free survival, and overall survival (Table 3 ).

The randomized phase II/III trial of neoadjuvant chemotherapy with gemcitabine and S-1 (an oral fluoropyrimidine derivative) versus initial surgery for resectable pancreatic cancer (PREP02/JSAP05) (UMIN000009634) by Unno et al., ${ }^{60}$ has the primary endpoints, the resection rate (RR) and overall survival, in the phase II and III respectively. 360 patients were enrolled at 57 centers. The median overall survival for the perioperative group was 37 versus 27 months in the adjuvant group, reaching a hazard ratio of 0.72 (95\% CI $0.55-094 ; p=0.015)$ in favor of perioperative therapy. However, the RR and operation morbidity were equivalent in the two groups. While we await a formal report, these findings point to the benefit of using neoadjuvant therapy for patients with resectable PDAC. $^{60}$

Neoadjuvant plus adjuvant or only adjuvant Nab-Paclitaxel 
Table 3. Selected ongoin trials of neoadyuvant therapy for RESECTABLE PDAC

\begin{tabular}{|c|c|c|c|c|c|c|}
\hline Trial (ID) author & Phase & $\begin{array}{c}\text { Target } \\
\mathrm{N}\end{array}$ & $\begin{array}{l}\text { Actual } \\
\mathrm{N}\end{array}$ & Regimen & $\begin{array}{l}\text { Primary } \\
\text { endpoint }\end{array}$ & Current status \\
\hline \multicolumn{7}{|l|}{ Neoajuvant chemotherapy } \\
\hline Prep02/JSAP05 & & & & $\begin{array}{l}\text { Neoadjuvant gemcitabine+ } \\
\text { S1 and adjuvant } \mathrm{S} 1\end{array}$ & & \\
\hline UMIN000009634 & II/III & 364 & 360 & vs. Adjuvant S1 & OS & $\begin{array}{l}\text { The median overall survival for } \\
\text { the perioperative group was } \\
36.7 \text { vs. } 26 \text { months }\end{array}$ \\
\hline \multicolumn{7}{|l|}{ Michiaki Unno (Japan) } \\
\hline PACT-15 Multicenter & & & & Neoadjuvant+adjuvant PEXG & EFS (1 yr) & Completed \\
\hline NCT 01150630 & II/III & 98 & 88 & vs. Adjuvant PEXG & OS & $\begin{array}{l}\text { The median survival } 38, \\
2 \text { (mo) and OS at } 3 \text { and } \\
5 \text { years ( } 55 \% \text { and } 49 \% \text {, } \\
\text { respectively), in favor of } \\
\text { Neoadjuvant }\end{array}$ \\
\hline Michele Reni (Milan-Italy) & & & & Vs. Adjuvant gemcitabine & & \\
\hline PANACHE01/PRODIGE 48 & $\begin{array}{l}\text { Multi- } \\
\text { center }\end{array}$ & & & $\begin{array}{l}\text { Neoadjuvant FOLFIRINOX } \\
\times 4+\text { adjuvant } \times 4\end{array}$ & & $\begin{array}{l}\text { The study is currently } \\
\text { recruiting participants }\end{array}$ \\
\hline NCT 02959879 & II & 160 & 160 & $\begin{array}{l}\text { vs. Neoadjuvant FOLFOX } \times 4 \\
\text { +adjuvant chemotherapy } \times 4\end{array}$ & OS & $\begin{array}{l}\text { The results of this study are } \\
\text { expected soon }\end{array}$ \\
\hline \multicolumn{4}{|l|}{$\begin{array}{l}\text { Lilian Schwarz (French) } \\
\text { NEONAX }\end{array}$} & \multicolumn{3}{|c|}{ vs. Adjuvant chemotherapy estándar $\times 6$} \\
\hline \multicolumn{2}{|l|}{ MCT 02047513} & & & \multicolumn{3}{|c|}{$\begin{array}{l}\text { Neoadjuvant and adjuvant nab-paclitaxel+ } \\
\text { gemcitabine DFS }\end{array}$} \\
\hline AIO-PACK-0313 & II & 166 & 127 & $\begin{array}{l}\text { vs. Adjuvant nab-paclitaxel+ } \\
\text { gemcitabine }\end{array}$ & DFS & $\begin{array}{l}\text { The study is still in } \\
\text { the recruitment phase }\end{array}$ \\
\hline \multicolumn{7}{|c|}{ Thomas Seufferlein (Germany) } \\
\hline SWOG 51505 & & & & $\begin{array}{l}\text { Neoadjuvant plus adjuvant } \\
\text { FOLFIRINOX VS }\end{array}$ & & Complete recriutment \\
\hline NCT02562716 & II & 112 & 112 & $\begin{array}{l}\text { neoadjuvant plus adjuvant } \\
\text { nab-paclitaxel+gemcitabine }\end{array}$ & OS & The study is ongiong \\
\hline \multicolumn{7}{|l|}{ Davendra Sohal (USA) } \\
\hline NEPAFOX & & & & $\begin{array}{l}\text { Neoadjuvant FOLFIRINOX } \\
\text { +adjuvant FOLFIRINOX }\end{array}$ & & \\
\hline $\begin{array}{l}\text { NCT01272976 } \\
\text { Salah-Eddin (Germany) }\end{array}$ & II/III & 126 & 40 & vs. adjuvant gemcitabine & OS & The study is ongiong \\
\hline NorPACT-1 & $\begin{array}{l}\text { Multi- } \\
\text { center }\end{array}$ & & & \multicolumn{3}{|c|}{$\begin{array}{l}\text { Neoadjuvant FOLFIRINOX } \times 4 \\
\text { +adjuvant gemcitabine }+ \text { capecitabine } \times 4\end{array}$} \\
\hline NCT02919787 & II/III & 90 & 90 & $\begin{array}{l}\text { vs. Adjuvant } \\
\text { gemvitabine/capecitabine } \times 6\end{array}$ & OS & The study is ongiong \\
\hline \multicolumn{7}{|l|}{ Svein Dueland (Oslo-Norway) } \\
\hline NEOPAC & & & & $\begin{array}{l}\text { Neoadjuvant GEMOX+ } \\
\text { adjuvant gemcitabine }\end{array}$ & & Study stopped \\
\hline $\begin{array}{l}\text { NCT01314027 } \\
\text { Heinrich (Zurich) }\end{array}$ & III & 310 & 38 & vs. adjuvant gemcitabine & RFS & low recruitment \\
\hline \multicolumn{7}{|l|}{ Neoadyuvant chemoradiation } \\
\hline NEOPA & $\begin{array}{l}\text { Multi- } \\
\text { center }\end{array}$ & & & $\begin{array}{l}\text { Neoadjuvant gemcitabine/ } \\
\text { XRT+adjuvant gemcitabine }\end{array}$ & & \\
\hline NCT 01900327 & III & 410 & 32 & vs. adjuvant gemcitabine only & OS & $\begin{array}{l}\text { The study terminated earlier } \\
\text { without reporting results. } \\
\text { Low recruitment }\end{array}$ \\
\hline
\end{tabular}

ID, indentification; GEMOX, gemcitabine/Oaliplatin; S1, an oral fluoropyrimidine derivative; PEXG, cisplatin, epirubicin, capecitabine, gemcitabine; RFS, recurrence-free survival; N, number of patients; OS, Overall survivial; DFS, disease-free survival; EFS, event-free survival; yr, year 
plus gemcitabine for resectable pancreatic cancer, a prospective, randomized, controlled, phase II study of the AIO (German Cancer Society Medical Oncology Task Force) Pancreas Cancer Group. NEONAX (AIO-PACK-0313, NCT 02047513). Evaluates nab-paclitaxel plus gemcitabine 2 preoperative cycles (nab paclitaxel $125 \mathrm{mg} / \mathrm{m}^{2}$, gemcitabine $1000 \mathrm{mg} / \mathrm{m}^{2}, 4$ cycles) plus surgery with subsequent adjuvant therapy (after 12 weeks post-surgery), vs. surgery first followed by adjuvant chemotherapy with 6 cycles of nab-paclitaxel/gemcitabine. The recruitment target is 166 patients, but the trial is still in the recruitment phase. The main objective of the study is DFS. ${ }^{61}$

Another randomized multicenter phase II/III study with adjuvant gemcitabine versus neoadjuvant/adjuvant FOLFIRINOX for resectable pancreatic carcinoma. NEPAFOX (NCT 02172976). It is in progress; the recruitment goal is 126 patients and currently have recruited 40 . The main objective is overall survival, and the secondary objectives are progression-free survival, perioperative morbidity and mortality, resection rate $\mathrm{R} 0$, tolerability and viability of neoadjuvant FOLFIRINOX. ${ }^{62}$

A study comparing two perioperative therapies with different neoadjuvant treatment regimens is underway by The Southwest Oncology Group (SWOG) S1505 a randomized phase II study of perioperative mFOLFIRINOX versus gemcitabine/nab-paclitaxel as therapy for resectable pancreatic adenocarcinoma (NCT02562716). This phase II trial studie has as the primary end point is overall survival. ${ }^{63}$

Norwegian Pancreatic Cancer Trial NorPACT-1 (NCT 02919787), is a multicenter, randomized, controlled phase III trial organized by the Norwegian Gastrointestinal Cancer Group for Hepatobiliopancreatic Cancer. Patients with resectable adenocarcinoma of the head of the pancreas are randomized into two groups, group 1: Surgery first or group 2: Neoadjuvant chemotherapy with four cycles of FOLFIRINOX followed by resection. Both groups receive adjuvant chemotherapy with gemcitabine and capecitabine. In total, 90 patients will be randomly assigned to the five norwegian university hospitals that perform pancreatic surgery. The primary objective is overall survival. ${ }^{64}$

PANACHE01-PRODIGE48 (NCT02959879), is a french (Schwarz et al. ${ }^{65}$ ), open, noncomparative, randomized, multicenter phase II study designed to evaluate the safety and efficacy of two neoadjuvant chemotherapy modalities (mFOLFIRINOX and FOLFOX, both followed by surgery with subsequent standard adjuvant therapy) compared to the current standard treatment (surgery+adjuvant chemotherapy) for resectable PDAC. The main targets are the 12-month OS rate and the rate of patients undergoing the full therapeutic sequence. The results of this study are expected by december 2021.

The NEOPAC trial (NCT01314027), from the University of Zurich with Stefan Heinrich as principal investigator is a randomized phase III study comparing neoadjuvant plus adjuvant treatment in resectable pancreatic cancer, gemcitabine/oxaliplatin (GEMOX) versus gemcitabine. The expected recruitment was 310 patients 155 in each arm, but the study has been stopped with 38 patients for low recruitment. ${ }^{66}$

For the first time, a Phase III multicenter study, NEOPA (NCT01900327, DRKS00003893, ISRCTN82191749), prospectively and randomly evaluates the impact of sequential neoadjuvant CRT followed by curative surgery vs primary surgery alone for resectable, non metastasized pancreatic adenocarcinoma. The main objective, was to evaluate the 3-year overall survival rate and the recruitment target was 410 patients, but the study was stopped earlier with 32 patients, due to difficulty in recruitment of patients, without reporting any results. ${ }^{67}$

\section{CONCLUSIONS}

More than two decades of active research have not yet defined the role of neoadjuvant therapy in resectable pancreatic cancer. As is well known, pancreatic cancer is an early biologically aggressive cancer with a predilection for early metastatic spread to the liver, peritoneum and lung. Although resection of the primary tumor appears necessary for long-term survival, it is not sufficient and a neoadjuvant treatment approach emphasizes early administration of systemic therapy, allowing a period of time to identify patients with aggressive tumor biology who are unlikely to benefit from surgical therapy. While it is important to ensure the administration of multimodal therapy to all patients with resectable PDAC to increase their chances of cure, it is equally important to develop an optimal, customized sequential treatment plan with multidisciplinary input from the time of initial diagnosis with the broader oncologic goal of eliminating both macroscopic and microscopic disease. 
Several phase II trials have shown encouraging results in terms of survival, but most of them have some limitations (few patients, unique centers, and great heterogeneity), so a number of fundamental questions remain, including the role of radiotherapy in addition to chemotherapy, optimal chemotherapy regimens, and the timing and duration of perioperative treatment. In contrast to an initial surgical approach, sequencing of neoadjuvant treatment will ensure that all patients receive systemic therapy and will improve discrimination between patients who will receive and those who will not benefit from surgery.

Given the data showing the survival benefit of chemotherapy both in the neoadjuvant and adjuvant setting when compared with no chemotherapy, it has become clear that chemotherapy, either before or after surgery, is a crucial component in the treatment in PDAC.

Currently regimens are not unified and vary among institutions, yet there is growing acceptance of this modality and it is expected that it will incorporate novel drug therapies and consolidate neoadjuvant systemic therapy strategies from diagnosis.

\section{ORCID}

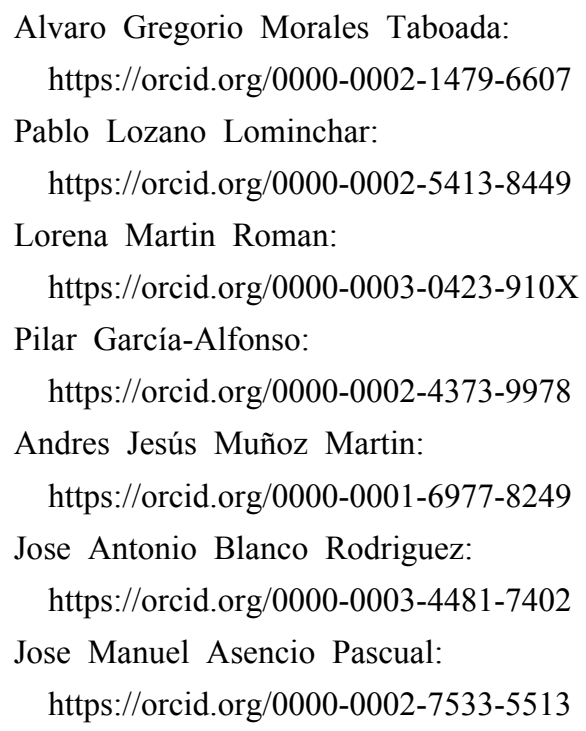

\section{AUTHOR CONTRIBUTIONS}

Conceptualization: AGMT. Data collection: AGMT, PLL, LMR. Formal analysis: AGMT, JMAP. Methodology: AGMT, PLL, JMAP. Project administration: AGMT, PGA, AJMM, JABR. Writing - original draft: AGMT.
Writing - review \& editing: AGMT, PLL, PGA, AJMM, JABR, JMAP.

\section{REFERENCES}

1. Rahib L, Smith BD, Aizenberg R, Rosenzweig AB, Fleshman JM, Matrisian LM. Projecting cancer incidence and deaths to 2030: the unexpected burden of thyroid, liver, and pancreas cancers in the United States. Cancer Res 2014;74:2913-2921.

2. Griffin JF, Smalley SR, Jewell W, Paradelo JC, Reymond RD, Hassanein RE, et al. Patterns of failure after curative resection of pancreatic carcinoma. Cancer 1990;66:56-61.

3. Sohn TA, Yeo CJ, Cameron JL, Koniaris L, Kaushal S, Abrams RA, et al. Resected adenocarcinoma of the pancreas-616 patients: results, outcomes, and prognostic indicators. J Gastrointest Surg 2000;4:567-579.

4. Ducreux M, Cuhna AS, Caramella C, Hollebecque A, Burtin P, Goéré D, et al. Cancer of the pancreas: ESMO Clinical Practice Guidelines for diagnosis, treatment and follow-up. Ann Oncol 2015;26 Suppl 5:v56-v68.

5. Kalser MH, Ellenberg SS. Pancreatic cancer. Adjuvant combined radiation and chemotherapy following curative resection. Arch Surg 1985;120:899-903.

6. Neoptolemos JP, Stocken DD, Friess H, Bassi C, Dunn JA, Hickey $\mathrm{H}$, et al. A randomized trial of chemoradiotherapy and chemotherapy after resection of pancreatic cancer. N Engl J Med 2004;350:1200-1210.

7. Oettle H, Neuhaus P, Hochhaus A, Hartmann JT, Gellert K, Ridwelski K, et al. Adjuvant chemotherapy with gemcitabine and long-term outcomes among patients with resected pancreatic cancer: the CONKO-001 randomized trial. JAMA 2013;310:1473-1481.

8. Neoptolemos JP, Palmer DH, Ghaneh P, Psarelli EE, Valle JW, Halloran CM, et al. Comparison of adjuvant gemcitabine and capecitabine with gemcitabine monotherapy in patients with resected pancreatic cancer (ESPAC-4): a multicentre, open-label, randomised, phase 3 trial. Lancet 2017;389:1011-1024.

9. Conroy T, Hammel P, Hebbar M, Abdelghani MB, Wei AC, Raoul JL, et al. Unicancer GI PRODIGE 24/CCTG PA.6 trial: a multicenter international randomized phase III trial of adjuvant mFOLFIRINOX versus gemcitabine (gem) in patients with resected pancreatic ductal adenocarcinomas. J Clin Oncol 2018;36(18 Suppl): LBA4001.

10. Labori KJ, Katz MH, Tzeng CW, Bjørnbeth BA, Cvancarova M, Edwin B, et al. Impact of early disease progression and surgical complications on adjuvant chemotherapy completion rates and survival in patients undergoing the surgery first approach for resectable pancreatic ductal adenocarcinoma- a population-based cohort study. Acta Oncol 2016;55:265-277.

11. Tzeng CW, Tran Cao HS, Lee JE, Pisters PW, Varadhachary GR, Wolff RA, et al. Treatment sequencing for resectable pancreatic cancer: influence of early metastases and surgical complications on multimodality therapy completion and survival. J Gastrointest Surg 2014;18:16-24; discussion 24-25.

12. Syed AR, Carleton NM, Horne Z, Dhawan A, Bedi G, Kochhar G, et al. Survival Trends for resectable pancreatic cancer using a multidisciplinary conference: the impact of post-operative chemotherapy. J Gastrointest Cancer 2020;51:836-843.

13. Neoptolemos JP, Stocken DD, Bassi C, Ghaneh P, Cunningham $D$, Goldstein D, et al. Adjuvant chemotherapy with fluorouracil plus folinic acid vs gemcitabine following pancreatic cancer resection: a randomized controlled trial. JAMA 2010;304:1073-1081.

14. Lim KH, Chung E, Khan A, Cao D, Linehan D, Ben-Josef E, 
et al. Neoadjuvant therapy of pancreatic cancer: the emerging paradigm? Oncologist 2012;17:192-200.

15. Tienhoven GV, Versteijne E, Suker M, Groothuis KBC, Busch OR, Bonsing BA, et al. Preoperative chemoradiotherapy versus immediate surgery for resectable and borderline resectable pancreatic cancer (PREOPANC-1): a randomized, controlled, multicenter phase III trial. J Clin Oncol 2018;36(18 Suppl):LBA4002.

16. Lutz MP, Zalcberg JR, Ducreux M, Aust D, Bruno MJ, Büchler MW, et al. Gallen EORTC Gastrointestinal Cancer Conference: consensus recommendations on controversial issues in the primary treatment of pancreatic cancer. Eur J Cancer 2017;79:41-49.

17. Chun YS, Pawlik TM, Vauthey JN. 8th Edition of the AJCC cancer staging manual: pancreas and hepatobiliary cancers. Ann Surg Oncol 2018;25:845-847.

18. Evans DB, George B, Tsai S. Non-metastatic pancreatic cancer: resectable, borderline resectable, and locally advanced-definitions of increasing importance for the optimal delivery of multimodality therapy. Ann Surg Oncol 2015;22:3409-3413.

19. Christians KK. New classification of locally advanced pancreatic cancer. In: Tsai S, Ritch P, Erickson B, Evans D, ed. Management of localized pancreatic cancer. Cham: Springer, 2019:97103.

20. National Comprehensive Cancer Network (NCCN). NCCN clinical practice guidelines in oncology- pancreatic adenocarcinoma version 1 [Internet]. Plymouth Meeting: NCCN 2019 [cited 2020 Mar 20]. Available from: https://www.nccn.org/professionals/physi cian_gls/pdf/pancreatic_blocks.pdf

21. Callery MP, Chang KJ, Fishman EK, Talamonti MS, William Traverso L, Linehan DC. Pretreatment assessment of resectable and borderline resectable pancreatic cancer: expert consensus statement. Ann Surg Oncol 2009;16:1727-1733.

22. Katz MH, Pisters PW, Evans DB, Sun CC, Lee JE, Fleming JB, et al. Borderline resectable pancreatic cancer: the importance of this emerging stage of disease. J Am Coll Surg 2008;206:833-846; discussion 846-848.

23. Vauthey JN, Dixon E. AHPBA/SSO/SSAT Consensus Conference on Resectable and Borderline Resectable Pancreatic Cancer: rationale and overview of the conference. Ann Surg Oncol 2009;16:1725-1726.

24. Regine WF, Winter KA, Abrams RA, Safran H, Hoffman JP, Konski A, et al. Fluorouracil vs gemcitabine chemotherapy before and after fluorouracil-based chemoradiation following resection of pancreatic adenocarcinoma: a randomized controlled trial. JAMA 2008;299:1019-1026.

25. Neoptolemos JP, Stocken DD, Bassi C, Ghaneh P, Cunningham $\mathrm{D}$, Goldstein D, et al. Adjuvant chemotherapy with fluorouracil plus folinic acid vs gemcitabine following pancreatic cancer resection: a randomized controlled trial. JAMA 2010;304:1073-1081.

26. Gnerlich JL, Luka SR, Deshpande AD, Dubray BJ, Weir JS, Carpenter $\mathrm{DH}$, et al. Microscopic margins and patterns of treatment failure in resected pancreatic adenocarcinoma. Arch Surg 2012;147:753-760

27. Sohal DP, Walsh RM, Ramanathan RK, Khorana AA. Pancreatic adenocarcinoma: treating a systemic disease with systemic therapy. J Natl Cancer Inst 2014;106:dju011.

28. Khorana AA, Mangu PB, Berlin J, Engebretson A, Hong TS, Maitra A, et al. Potentially Curable Pancreatic Cancer: American Society of Clinical Oncology Clinical Practice Guideline update. J Clin Oncol 2017;35:2324-2328.

29. Wu W, He J, Cameron JL, Makary M, Soares K, Ahuja N, et al. The impact of postoperative complications on the administration of adjuvant therapy following pancreaticoduodenectomy for adenocarcinoma. Ann Surg Oncol 2014;21:2873-2881.

30. Conroy T, Hammel P, Hebbar M, Ben Abdelghani M, Wei AC,
Raoul JL, et al. FOLFIRINOX or gemcitabine as adjuvant therapy for pancreatic cancer. N Engl J Med 2018;379:2395-2406.

31. Ohigashi H, Ishikawa O, Eguchi H, Takahashi H, Gotoh K, Yamada T, et al. Feasibility and efficacy of combination therapy with preoperative full-dose gemcitabine, concurrent three-dimensional conformal radiation, surgery, and postoperative liver perfusion chemotherapy for T3-pancreatic cancer. Ann Surg 2009;250:88-95.

32. Heinrich S, Schäfer M, Weber A, Hany TF, Bhure U, Pestalozzi $\mathrm{BC}$, et al. Neoadjuvant chemotherapy generates a significant tumor response in resectable pancreatic cancer without increasing morbidity: results of a prospective phase II trial. Ann Surg 2008;248:1014-1022.

33. Oettle H, Post S, Neuhaus P, Gellert K, Langrehr J, Ridwelski $\mathrm{K}$, et al. Adjuvant chemotherapy with gemcitabine vs observation in patients undergoing curative-intent resection of pancreatic cancer: a randomized controlled trial. JAMA 2007;297:267-277.

34. Versteijne E, Suker M, Groothuis K, Akkermans-Vogelaar JM, Besselink MG, Bonsing BA, et al. Preoperative chemoradiotherapy versus immediate surgery for resectable and borderline resectable pancreatic cancer: results of the Dutch randomized phase III PREOPANC trial. J Clin Oncol 2020;38:17631773 .

35. van der Gaag NA, Rauws EA, van Eijck $\mathrm{CH}$, Bruno MJ, van der Harst E, Kubben FJ, et al. Preoperative biliary drainage for cancer of the head of the pancreas. N Engl J Med 2010;362:129137.

36. Dhir M, Malhotra GK, Sohal DPS, Hein NA, Smith LM, O'Reilly EM, et al. Neoadjuvant treatment of pancreatic adenocarcinoma: a systematic review and meta-analysis of 5520 patients. World J Surg Oncol 2017;15:183.

37. Haeberle L, Esposito I. Pathology of pancreatic cancer. Transl Gastroenterol Hepatol 2019;4:50.

38. Quiros RM, Brown KM, Hoffman JP. Neoadjuvant therapy in pancreatic cancer. Cancer Invest 2007;25:267-273.

39. Evans DB, Rich TA, Byrd DR, Cleary KR, Connelly JH, Levin $\mathrm{B}$, et al. Preoperative chemoradiation and pancreaticoduodenectomy for adenocarcinoma of the pancreas. Arch Surg 1992;127: 1335-1339.

40. Pisters PW, Abbruzzese JL, Janjan NA, Cleary KR, Charnsangavej C, Goswitz MS, et al. Rapid-fractionation preoperative chemoradiation, pancreaticoduodenectomy, and intraoperative radiation therapy for resectable pancreatic adenocarcinoma. J Clin Oncol 1998; 16:3843-3850.

41. Calvo FA, Matute R, García-Sabrido JL, Gómez-Espí M, Martínez NE, Lozano MA, et al. Neoadjuvant chemoradiation with tegafur in cancer of the pancreas: initial analysis of clinical tolerance and outcome. Am J Clin Oncol 2004;27:343-349.

42. Hoffman JP, Lipsitz S, Pisansky T, Weese JL, Solin L, Benson $\mathrm{AB} 3 \mathrm{rd}$. Phase II trial of preoperative radiation therapy and chemotherapy for patients with localized, resectable adenocarcinoma of the pancreas: an Eastern Cooperative Oncology Group Study. J Clin Oncol 1998;16:317-323.

43. Evans DB, Varadhachary GR, Crane CH, Sun CC, Lee JE, Pisters PW, et al. Preoperative gemcitabine-based chemoradiation for patients with resectable adenocarcinoma of the pancreatic head. J Clin Oncol 2008;26:3496-3502.

44. Varadhachary GR, Wolff RA, Crane CH, Sun CC, Lee JE, Pisters PW, et al. Preoperative gemcitabine and cisplatin followed by gemcitabine-based chemoradiation for resectable adenocarcinoma of the pancreatic head. J Clin Oncol 2008;26:34873495 .

45. Christians KK, Heimler JW, George B, Ritch PS, Erickson BA, Johnston F, et al. Survival of patients with resectable pancreatic 
cancer who received neoadjuvant therapy. Surgery 2016;159:893900.

46. Winter JM, Brennan MF, Tang LH, D'Angelica MI, Dematteo $\mathrm{RP}$, Fong $\mathrm{Y}$, et al. Survival after resection of pancreatic adenocarcinoma: results from a single institution over three decades. Ann Surg Oncol 2012;19:169-175.

47. Pisters PW, Wolff RA, Janjan NA, Cleary KR, Charnsangavej $\mathrm{C}$, Crane $\mathrm{CN}$, et al. Preoperative paclitaxel and concurrent rapid-fractionation radiation for resectable pancreatic adenocarcinoma: toxicities, histologic response rates, and event-free outcome. J Clin Oncol 2002;20:2537-2544.

48. Talamonti MS, Small W Jr, Mulcahy MF, Wayne JD, Attaluri $\mathrm{V}$, Colletti LM, et al. A multi-institutional phase II trial of preoperative full-dose gemcitabine and concurrent radiation for patients with potentially resectable pancreatic carcinoma. Ann Surg Oncol 2006;13:150-158.

49. Palmer DH, Stocken DD, Hewitt H, Markham CE, Hassan AB, Johnson PJ, et al. A randomized phase 2 trial of neoadjuvant chemotherapy in resectable pancreatic cancer: gemcitabine alone versus gemcitabine combined with cisplatin. Ann Surg Oncol 2007; 14:2088-2096.

50. Heinrich S, Pestalozzi BC, Schäfer M, Weber A, Bauerfeind P, Knuth A, et al. Prospective phase II trial of neoadjuvant chemotherapy with gemcitabine and cisplatin for resectable adenocarcinoma of the pancreatic head. J Clin Oncol 2008;26:25262531.

51. O'Reilly EM, Perelshteyn A, Jarnagin WR, Schattner M, Gerdes $\mathrm{H}$, Capanu M, et al. A single-arm, nonrandomized phase II trial of neoadjuvant gemcitabine and oxaliplatin in patients with resectable pancreas adenocarcinoma. Ann Surg 2014;260:142-148.

52. Casadei R, Di Marco M, Ricci C, Santini D, Serra C, Calculli $\mathrm{L}$, et al. Neoadjuvant chemoradiotherapy and surgery versus surgery alone in resectable pancreatic cancer: a single-center prospective, randomized, controlled trial which failed to achieve accrual targets. J Gastrointest Surg 2015;19:1802-1812.

53. Golcher H, Brunner TB, Witzigmann H, Marti L, Bechstein WO, Bruns C, et al. Neoadjuvant chemoradiation therapy with gemcitabine/cisplatin and surgery versus immediate surgery in resectable pancreatic cancer: results of the first prospective randomized phase II trial. Strahlenther Onkol 2015;191:7-16.

54. Reni M, Balzano G, Zanon S, Zerbi A, Rimassa L, Castoldi R, et al. Safety and efficacy of preoperative or postoperative chemotherapy for resectable pancreatic adenocarcinoma (PACT-15): a randomised, open-label, phase 2-3 trial. Lancet Gastroenterol Hepatol 2018;3:413-423.

55. Lutfi W, Talamonti MS, Kantor O, Wang CH, Stocker SJ, Bentrem DJ, et al. Neoadjuvant external beam radiation is associated with no benefit in overall survival for early stage pancreatic cancer. Am J Surg 2017;213:521-525.

56. Mokdad AA, Minter RM, Zhu H, Augustine MM, Porembka MR, Wang SC, et al. Neoadjuvant therapy followed by resection versus upfront resection for resectable pancreatic cancer: a propensity score matched analysis. J Clin Oncol 2017;35:515-522.

57. Cloyd JM, Chen HC, Wang X, Tzeng CD, Kim MP, Aloia TA, et al. Chemotherapy versus chemoradiation as preoperative therapy for resectable pancreatic ductal adenocarcinoma: a propensity score adjusted analysis. Pancreas 2019;48:216-222.

58. Mokdad AA, Minter RM, Yopp AC, Porembka MR, Wang SC, $\mathrm{Zhu} \mathrm{H}$, et al. Comparison of overall survival between preoperative chemotherapy and chemoradiotherapy for resectable pancreatic adenocarcinoma. J Natl Compr Canc Netw 2018;16: 1468-1475.

59. Xiang M, Heestand GM, Chang DT, Pollom EL. Neoadjuvant treatment strategies for resectable pancreas cancer: a propensitymatched analysis of the National Cancer Database. Radiother Oncol 2020;143:101-107.

60. Unno M, Motoi F, Matsuyama Y, Satoi S, Matsumoto I, Aosasa $\mathrm{S}$, et al. Randomized phase II/III trial of neoadjuvant chemotherapy with gemcitabine and S-1 versus upfront surgery for resectable pancreatic cancer (Prep-02/JSAP-05). J Clin Oncol 2019; $37(4$ Suppl):189.

61. Ettrich TJ, Berger AW, Perkhofer L, Daum S, König A, Dickhut A, et al. Neoadjuvant plus adjuvant or only adjuvant nab-paclitaxel plus gemcitabine for resectable pancreatic cancer- the NEONAX trial (AIO-PAK-0313), a prospective, randomized, controlled, phase II study of the AIO pancreatic cancer group. BMC Cancer 2018;18:1298.

62. Hozaeel W, Pauligk C, Homann N, Luley K, Kraus TW, Trojan $\mathrm{J}$, et al. Randomized multicenter phase II/III study with adjuvant gemcitabine versus neoadjuvant/adjuvant FOLFIRINOX in resectable pancreatic cancer: The NEPAFOX trial. J Clin Oncol 2015;33(15 Suppl):TPS4152.

63. Sohal D, McDonough SL, Ahmad SA, Gandhi N, Beg MS, Wang-Gillam A, et al. SWOG S1505: a randomized phase II study of perioperative mFOLFIRINOX vs. gemcitabine/nab-paclitaxel as therapy for resectable pancreatic adenocarcinom. J Clin Oncol 2017;35(4 Suppl):TPS508.

64. Labori KJ, Lassen K, Hoem D, Grønbech JE, Søreide JA, Mortensen K, et al. Neoadjuvant chemotherapy versus surgery first for resectable pancreatic cancer (Norwegian Pancreatic Cancer Trial - 1 (NorPACT-1)) - study protocol for a national multicentre randomized controlled trial. BMC Surg 2017;17:94.

65. Schwarz L, Vernerey D, Bachet JB, Tuech JJ, Portales F, Michel $\mathrm{P}$, et al. Resectable pancreatic adenocarcinoma neo-adjuvant FOLF(IRIN)OX-based chemotherapy - a multicenter, non-comparative, randomized, phase II trial (PANACHE01-PRODIGE48 study). BMC Cancer 2018;18:762.

66. Heinrich S, Pestalozzi B, Lesurtel M, Berrevoet F, Laurent S, Delpero JR, et al. Adjuvant gemcitabine versus NEOadjuvant gemcitabine/oxaliplatin plus adjuvant gemcitabine in resectable pancreatic cancer: a randomized multicenter phase III study (NEOPAC study). BMC Cancer 2011;11:346.

67. Tachezy M, Gebauer F, Petersen C, Arnold D, Trepel M, Wegscheider K, et al. Sequential neoadjuvant chemoradiotherapy (CRT) followed by curative surgery vs. primary surgery alone for resectable, non-metastasized pancreatic adenocarcinoma: NEOPAa randomized multicenter phase III study (NCT01900327, DRK S00003893, ISRCTN82191749). BMC Cancer 2014;14:411. 